\title{
OS APLICATIVOS WHATSAPP E IMO COMO POTENCIALIZADORES DE APRENDIZAGENS E INTERAÇÃO PARA UM GRUPO DE SURDOS
}

\author{
Kelli Cristina Freitas Trindade \\ Ieda Maria Giongo ${ }^{1}$ \\ Morgana Domênica Hattge
}

\begin{abstract}
Resumo: Este artigo tem como objetivo problematizar o uso dos aplicativos Whatsapp e Imo como produtores de aprendizagens e interaçóes para um grupo de surdos que semanalmente se reúne em espaços informais. A investigação se constituiu em uma abordagem qualitativa, tendo gerado o material de pesquisa por meio de observaçôes, caderno de campo, imagens/Print screen da tela do smartphone e entrevistas (videogravadas e, posteriormente, transcritas), realizadas com o grupo pesquisado. A análise do material de pesquisa se deu por meio de algumas ferramentas foucaultianas, em especial as noçóes de enunciação, enunciado e discurso. Os resultados apontam que o uso dos aplicativos analisados ampliam a interação e comunicação do grupo de surdos entre eles, com a família e a sociedade. Ademais, potencializam os processos de aprendizagem por meio de buscas na internet, pesquisas e debates.
\end{abstract}

Palavras-chave: Cultura Surda; WhatsApp; Imo; comunicação; interação.

\section{APPLICATIONS WHATSAPP AND IMO TO POTENTIALIZE LEARNING AND INTERACTION IN A GROUP OF DEAF INDIVIDUALS}

\begin{abstract}
This article aims at analyzing the use of applications WhatsApp and Imo to produce learning and interaction in a group of deaf individuals who gather weekly in informal venues. The investigation happened through a qualitative approach, which generated research material such as observations, field notebooks, smartphones images/print screens and interviews (taped and subsequently transcribed) carried out with the group studied. Analysis of the research material occurred through foucauldian tools, especially the notions of enunciation, utterance and discourse. The outcomes point out to the fact that these applications increase interaction and communication
\end{abstract}

1 Professora vinculada ao Centro de Ciências Exatas e Tecnológicas e ao Mestrado Profisisonal em Ensino de Ciências Exatas. 
in the group of deaf individuals, among themselves, their families and society. They also promote learning processes through internet searches, research and debates.

Keywords: Deaf Culture, WhatsApp, Imo, communication, interaction.

\section{O tema e o grupo pesquisado}

Este artigo se constitui em um recorte de uma dissertação que problematizou o uso dos aplicativos Whatsapp e $I_{m}^{2} o^{2}$ como produtores de aprendizagens e interaçóes para um grupo de surdos que semanalmente se reúne em espaços informais. A dinâmica de encontros tem ocorrido, há tempos, semanalmente, na residência de uma intérprete que deles participa. O número médio de surdos presentes nesses encontros tem sido, em média, quinze; com idade entre doze e trinta e cinco anos. Alguns encontros costumam ser realizados na casa de um dos integrantes para a qual os demais são convidados e, para otimizar o tempo, a reuniáo acontece no local. Com frequência, durante as discussões, os surdos participantes dessas reuniōes fazem uso de dois aplicativos que se encontram em seus smartphones, com ênfase WhatsApp e Imo. Em efeito, as oportunidades de interação e comunicaçáo que as tecnologias digitais vêm contemplando a sociedade, em geral, permite-nos refletir sobre a importância de realizar uma pesquisa focada nas potencialidades e limitaçóes que o uso dessas ferramentas proporciona aos surdos, em especial às questôes vinculadas à comunicação e interação.

A forma como o surdo se relaciona com o mundo está ligada à sua experiência de vida e, principalmente, à sua forma visual e espacial de se comunicar. Quando se desconhece as características desse indivíduo, torna-se difícil compreendê-lo, principalmente se for julgado pelo ponto de vista do ouvinte ${ }^{3}$, que usa a oralidade para se comunicar. Por conta disso, não ouvir acaba sendo uma limitação que o ouvinte atribuiu ao surdo.

Em efeito, a cultura dos indivíduos frequentemente é composta por características que os marcam, como a língua, hábitos, costumes, entre outros. Para Lopes e Veiga Neto (2006 p. 87), a "Cultura pode ser entendida como um conjunto de práticas capazes de serem significadas por um grupo de pessoas que vivem e sentem a experiência visual, no caso dos surdos, de uma forma semelhante". Mesmo assim, a dos surdos, por vezes, é considerada diminuta por ser composta de um pequeno grupo, não seletivo, sendo, dessa forma, discriminada.

Assim, o convívio com seus semelhantes é importante desde muito cedo, principalmente em espaços onde esse grupo se faz mais presente. Seus integrantes realizam as atividades do cotidiano de forma independente, trabalham normalmente, possuem uma vida produtiva. Entretanto, ainda é notório que passam muitas

2 À época do estudo, o WhatsApp ainda não apresentava a possibilidade de conversação por vídeos.

3 Ouvintes são todas as pessoas que ouvem e usam a língua oral para se comunicar e desenvolver. Segundo Quadros (2004, p. 10), "O termo 'ouvinte' se refere a todos aqueles que não compartilham as experiências visuais enquanto surdos". 
dificuldades em momentos em que náo conseguem se comunicar com os ouvintes. Nos espaços comuns, como em bancos e hospitais, às vezes, tentam se comunicar oralmente para serem compreendidos.

Durante o período da pesquisa, percebeu-se o quanto as tecnologias digitais estavam presentes na rotina desse grupo. De acordo com Kenski (2013, p. 61), "À velocidade em que acontece a inclusão das tecnologias, novas alteraçốes são provocadas nos diferentes campos da sociedade como no trabalho, no lazer, nos relacionamentos, entre outros" Durante as reuniōes informais das quais o grupo investigado participava, o uso do smartphone era comum e até necessário, tendo em vista que seus integrantes costumavam justificar atrasos, ausências, ou ainda buscar informaçôes sobre assuntos discutidos, entre outras demandas.

Nessa ótica, uma investigação que se ocupa em examinar as possibilidades e limitaçóes do uso de aplicativos como produtores de aprendizagens e interaçóes para um grupo de surdos que semanalmente se reúne em espaços informais pode ser potente para que se (re) pensem questóes vinculadas à cultura surda. Por conta disso, na próxima seção, examinamos alguns aspectos relativos às tecnologias e à cultura surda.

\section{Acerca de tecnologias digitais e surdez}

Os avanços das tecnologias digitais e o seu uso são vistos em todo momento no cotidiano. Kenski (2008) declara que tecnologia é um conjunto de técnicas e conhecimentos obtidos que pode contribuir para melhorar nossas vidas. E, a cada dia, surgem inovaçôes que superam invençóes já existentes que proporcionam maior conforto e comodidade à sociedade. Além de facilitar a comunicação e a vida de seus usuários, tais ferramentas vêm beneficiando especialmente pessoas com algumas limitaçóes, visto que permitem acesso a locais e informaçôes que antes eram inacessíveis em função das barreiras físicas de comunicação ou outras especificidades.

Para Kenski (2008, p. 21), "o homem transita culturalmente mediado pelas tecnologias que lhe são contemporâneas. Elas transformam sua maneira de pensar, agir e falar". Gadotti (2005, p. 03) afirma que tais oportunidades ultrapassam barreiras físicas e que "as múltiplas oportunidades de aprendizagens" disponibilizam novos espaços de conhecimento. Em efeito, as tecnologias digitais também têm proporcionado à nova geração de surdos o contato com os acontecimentos de forma rápida e dinâmica, permitindo acesso igualitário às informaçóes.

Em particular, os smartphones disponibilizam, mudam a concepçáo de espaço e distância, além de criarem novas linguagens. Em relação aos surdos, não apenas facilitam a rotina: são portas que se abrem para aprendizagens e convívio social que, por vezes, foram negligenciados em virtude da falta de comunicação com a família e a sociedade. Belloni (2014) expóe que as tecnologias digitais proporcionam aproximaçáo entre seus usuários e os surdos, mesmo quando não alfabetizados. Mediante seu uso, passam a ter maior possibilidade de comunicação, mesmo 
à distância, por meio de mensagens de texto pelo celular, ou de conversas com imagens e vídeos, entre outros serviços disponíveis pelas tecnologias digitais.

A esse respeito, Stumpf (2010 p.2) alude que "as novas tecnologias revolucionam o mundo das comunicaçôes e podem fazer com que ele seja mais acolhedor para os surdos", pois, por meio de ferramentas diversificadas, estes fazem uso de uma linguagem simples, e vêm ampliando sua comunicaçáo com ouvintes que náo dominam a língua de sinais. Quando o telefone surgiu, era uma tecnologia inviável para o surdo, já que o aparelho transmitia e recebia apenas a voz e, para usálo, dependia-se de um ouvinte para transmitir e receber as mensagens. Entretanto, segundo Oliveira (2007), os telefones inteligentes, como são conhecidos os smartphones, possibilitam às pessoas surdas a utilização desse aparelho de caráter dinâmico.

Ainda, Kenski (2013, p. 61) expressa que "À velocidade em que acontece a inclusão das tecnologias, novas alterações são provocadas nos diferentes campos da sociedade como no trabalho, no lazer, nos relacionamentos, entre outros". Os atuais aparelhos celulares possuem aplicativos que permitem enviar e receber mensagens instantâneas de qualquer lugar, desde que se tenha acesso à internet, proporcionando certa independência aos surdos, uma vez que muitas empresas e instituiçóes, como clínicas médicas, restaurantes e escolas, fazem uso dessas ferramentas.

Essas tecnologias proporcionam aos surdos acesso a informaçóes num curto espaço de tempo, deixando-os mais atualizados em relação aos acontecimentos do mundo. Moran (2012 p. 125) descreve que "A conectividade abre oportunidades muito variadas de aprendizagem personalizada, flexível, ubíqua, e integrada." Com acesso às tecnologias digitais que os smartphones disponibilizam, esse grupo passou a ter oportunidade de estudar conectado à internet e se comunicar com semelhantes e ouvintes por meio do Whatsapp, do Imo e também dos sites de relacionamentos, como Facebook, MSN, Instagram, Twitter, que, assim como outros, têm como finalidade o entretenimento, mas contribuem para estreitar laços sociais e ter acesso a diversos tipos de aprendizagens.

Embora as tecnologias digitais e suas ferramentas auxiliem na rotina, Stumpf (2010) explicita que nem todos os surdos conseguem usá-las. Tal fato se deve a questóes financeiras, sociais e até a dificuldade de comunicação desse grupo, haja vista a existência dos não alfabetizados e outros que não dominam a língua de sinais. Entretanto,

[...] outra barreira importante dificulta a total acessibilidade por parte dos surdos às novas tecnologias: elas são visuais, mas em sua grande maioria, demandam sujeitos alfabetizados. A população surda, em nosso país e na maioria dos países é, em grande parte, composta de analfabetos funcionais na escrita da língua oral do próprio país e as produçóes em Libras exigem a disponibilidade de vários artefatos de cultura como câmeras, vídeos, tradutores, intérpretes, etc. (STUMPF, 2010, p.2).

Como aponta Sumpf (2010), muitos aplicativos disponíveis exigem que os usuários sejam alfabetizados para serem mais bem utilizados e compreendidos. 
Porém, tanto WhatsApp, como o Imo dispóem de diversos símbolos que, muitas vezes, substituem palavras e continuam respeitando o contexto da mensagem a ser enviada, facilitando a comunicação e o uso pelos surdos que não são alfabetizados. Por meio desses aplicativos, seus usuários, principalmente os surdos, podem, mediante os vídeos elou suas chamadas, ter uma comunicação mais clara e objetiva pela língua de sinais.

Experimentar essas novas possibilidades de aprendizagens e interação que os surdos vêm vivenciando por meio dos aplicativos é algo muito comum entre os ouvintes, segundo Stumpf (2010). Antes, para um surdo conversar com alguém, precisava estar frente a frente; porém, hoje, ele tem a possibilidade de se comunicar com um amigo de outro estado ou país de forma simultânea: basta digitar um texto ou usar uma das ferramentas disponíveis nos aplicativos e gravar um vídeo, sinalizando ou até mesmo fazer uma chamada em vídeo.

Para os surdos as modificaçóes trazidas pelas novas tecnologias não foram apenas educativas, sociais e laborais, mas, sobretudo de inserçáo comunicativa em muitas das atividades da vida diária antes inacessíveis, pois, a distância e o tempo se encurtaram com o avento da Internet, e surgiram novas maneiras de relacionamento (STUMPF, 2010, p.5).

A seguir, explicitamos a metodologia de pesquisa e as escolhas teóricas que a sustentaram.

\section{Sobre a metodologia da investigaçáo}

Nesta seção, apontamos os procedimentos metodológicos que sustentaram a investigação. Esta se constituiu em qualitativa que, segundo Moreira (2009, p. 9), o "[...] predomínio dessa metodologia se dá na pesquisa em educação em geral e em ciências em particular [...]”. Para Creswell (2007, p.18), a pesquisa qualitativa apresenta "[...] significados múltiplos das experiências individuais, significados social e historicamente construídos, com o objetivo de desenvolver uma teoria ou um padrão". Ademais, também é potente [...] "em perspectivas reivindicatórias/ participatórias (ou seja, políticas, orientadas para a questão ou colaborativas, orientadas para a mudança) ou em ambas" (CRESWELL, 2007, p.18).

Aliado a isso, desenvolvemos a investigação via inspiração etnográfica, pois buscamos compreender o comportamento de um grupo. O método etnográfico possui características antropológicas e tem, como principais referências, a etnografia de povos estudados no início do século XX. Para Angrosino (2009, p. 30), "a etnografia é a arte e a ciência de descrever um grupo humano - suas instituiçóes, seus comportamentos interpessoais, suas produçôes materiais e suas crenças”. Ao optar por esse modelo de investigação, o pesquisador precisa ter interesse em conhecer e descrever o grupo estudado a ponto de buscar explicaçóes ou fundamentos para um fato ou fenômeno real que dele fazem parte.

Ainda com relação a aspectos metodológicos, a presente investigação fez uso da observação participante. Para Yin (2010, p.138), “A observação participante é 
uma modalidade especial de observação na qual você não é apenas um observador passivo". Angrosino (2009, p. 31) acrescenta que esse tipo de investigação não deve ser considerado um método de pesquisa quando isolado dos demais métodos, uma vez que ele é "contexto comportamental a partir do qual um etnógrafo usa técnicas específicas para coletar dados". Dessa forma, os materiais de pesquisa foram gerados por meio de registros das observaçóes em diário de campo, gravação dos encontros por meio de vídeos e textos postados no whatsapp.

Em termos analíticos, baseamo-nos em algumas ferramentas foucaultianas, por entendermos que a verdade é uma construção da história, tal como o sujeito é, com sua complexidade, emoçóes, natureza e experiências de vida. Sobre as práticas sociais, Foucault expressa que "podem chegar a engendrar domínios de saber que não somente fazem aparecer novos objetos, novos conceitos, novas técnicas, mas também fazem nascer formas totalmente novas de sujeitos e de sujeitos do conhecimento" (FOUCAULT, 2009, p. 08).

Por que a verdade? Por que nos preocupamos com a verdade, aliás, mais do que conosco? E por que somente cuidamos de nós mesmos através da preocupação com a verdade? É certamente, nesse campo da obrigação de verdade que é possível se deslocar, de uma maneira ou de outra, algumas vezes contra os efeitos de dominaçáo que podem estar ligados às estruturas de verdade ou às instituições encarregadas da verdade (FOUCAULT, 2004, p. 10).

Foucault $(2008$, p. 55) ainda expressa que o discurso não se limita à linguagem ou à fala, pois "certamente os discursos são feitos de signos; mas o que fazem é mais que utilizar esses signos para designar coisas" E completa expressando que "É esse mais que é preciso fazer aparecer e que é preciso descrever" (FOUCAULT, 2008, p.55). $O$ autor ainda acrescenta que

A análise do pensamento é sempre alegórica em relação ao discurso que utiliza. Sua questão, infalivelmente, é: o que se dizia no que estava dito? A análise do campo discursivo é orientada de forma inteiramente diferente; trata-se de compreender o enunciado na estreiteza e singularidade de sua situação; de determinar as condições de sua existência, de fixar seus limites da forma mais justa, de estabelecer suas correlaçóes com outros enunciados a que pode estar ligado, de mostrar que outras formas de enunciação excluí (FOUCAULT, 2008. p.31)

De acordo com o filósofo, não é possível uma enunciação ser idêntica à outra; no entanto, é possível que duas tenham um mesmo enunciado. Veiga-Neto (2000, p.25) acrescenta que "Esse emaranhado de séries discursivas institui um conjunto de significados mais ou menos estáveis que, ao longo de um período de tempo, funcionará como um amplo domínio simbólico no qual e através do qual daremos sentido [...]”.

Para problematizar o uso dos aplicativos para os surdos, criamos um grupo de discussão no aplicativo WhatsApp. Foram convidados para participarem os integrantes que frequentavam as reuniōes em um espaço informal. Assim, buscamos, por meio de imagens relacionadas à cultura surda e questionamentos, compreender de que forma tais tecnologias digitais vêm contribuindo para as aprendizagens, 
comunicação e interaçáo social desses sujeitos. Os encontros ocorreram em seis semanas, com uma média de três a quatro horas de duração.

Adotamos a mesma proposta de trabalho em todos os encontros. Inicialmente, elegíamos um tema para a semana. Os assuntos eram sempre voltados às áreas da surdez e da cultura surda. Selecionávamos as imagens, que eram retiradas da internet, e enviávamos pelo aplicativo WhatsApp para reflexão, discussão e análise do grupo. As imagens eleitas continham conceitos, ou representaçóes a respeito dos temas abordados. Algumas incluíam palavras ou frases de fácil compreensão para o grupo que teria acesso.

Elegemos, para cada semana, um assunto diferente a ser discutido, seguindo esta sequência: Setembro azul; Aparelhos auditivos e implante coclear; Língua Brasileira de Sinais - LIBRAS; Educação bilíngue e as preferências entre os aplicativos Whats $A p p$ e IMO. Posteriormente, nos encontros presenciais, dávamos continuidade aos questionamentos sobre as imagens e o tema abordado durante a semana no aplicativo.

Durante a realizaçáo das atividades desta pesquisa, os surdos participaram das açôes em momentos e locais diferentes: pelo aplicativo WhatsApp, na sede do grupo e em dois ambientes externos. Uma das reuniôes externas aconteceu na casa de uma surda participante do grupo; a outra, em uma escola estadual da região. Os encontros sempre começavam com informaçóes a respeito da agenda, dos compromissos, ou outra demanda relacionada aos componentes do grupo. Para o desenvolvimento das atividades, contamos com o auxílio de intérpretes. Ademais, utilizamos o Datashow para projetar as imagens a serem novamente expostas e discutidas.

Por questóes de ética em pesquisa, todos os participantes assinaram o Termo de Consentimento Livre e Esclarecido, sendo identificados pela letra A, seguida de um número, em ordem crescente. Na próxima seçáo, examinamos os resultados advindos com a análise dos materiais de pesquisa.

\section{Acerca das enunciaçóes: o que diz um grupo de surdos}

As enunciaçóes surdas são relatos de vida que geralmente começam na infância, passam pela família, escola, sociedade até a vida profissional. Enfim, a dificuldade em se comunicar acompanha esse tipo de deficiente desde sempre; no entanto, alguns relatos da sua vida contemporânea começam a ter um tom diferente, fato que se deve muito às tecnologias digitais e aos aplicativos disponíveis no mercado. Para Kenski (2008, p. 21) "o homem transita culturalmente mediado pelas tecnologias que lhes são contemporâneas. Elas transformam sua maneira de pensar agir e falar." $\mathrm{E}$, assim como os ouvintes, os surdos são usuários dessas ferramentas tecnológicas que o mercado oferece.

É importante ressaltar que não falamos de tecnologias específicas para os surdos. Estes, ao serem questionados, durante os encontros, se usavam algum aplicativo específico para surdos, responderam "não". Os três por eles mais citados 
foram Facebook $k^{4}$ WhatsApp e Imo. "Eu gosto mais do WhatsApp porque é mais fácil se comunicar, e também o Imo, porque abre a tela e conversa em LIBRAS, e isso é muito importante" (SURDA 04). Esses aplicativos náo foram desenvolvidos para um grupo específico, mas para ampliar a rede de relacionamento e comunicação geral. Em síntese, é possível inferir que, dentre outras possibilidades que os surdos têm como aplicativos, os do grupo pesquisado, preferiam aplicativos de uso comum e não algo desenvolvido especificamente para alguém com surdez. As enunciações a seguir expressam essa ideia.

Primeiro eu utilizo mais o WhatsApp e depois o Imo. Sou viciada, viciada, viciada no WhasApp. Eu mando fotos dos lugares e passeios, eu mando fotos nos grupos de pessoas que moram fora, tenho uma comunicaçáo, uma interação, trocando experiências é mais fácil (SURDO A 08).

WhatsApp é bom, o facebook, o Imo também é bom. Conversa em LIBRAS, com a câmera é muito bom (SURDO A 02).

Eu uso todo dia WhasApp, que uso as palavras para falar com as pessoas, o Imo também que utilizo para fazer vídeos com os surdos, ai eu vejo a pessoa, a gente conversa, usa LIBRAS, é melhor (SURDO A 04).

WhatsApp, Imo, Facebook. Minha irmã, às vezes, ajuda a entender Facebook (SURDO A 11).

Talvez, essas preferências sejam influências da sociedade, uma vez que, segundo o site techtudo (2017), o ranking de primeiro lugar, como aplicativo mais utilizado e atualmente baixado, é o WhatsApp, preferido por cerca de $80 \%$ dos brasileiros. Em segundo lugar, figura o Facebook; por sua vez, o Imo não apareceu entre os mais conhecidos e utilizados na pesquisa. Em relação ao Facebook, apesar de uma grande aceitação e uso por parte do grupo, não foi explorado nesta pesquisa, tendo em vista que o foco da investigaçáo repousou na comunicação e interaçáo por meio dos aplicativos de mensagens instantâneas. Hoje, estas são possíveis de serem estabelecidas por meio do Facebook; porém, outros aplicativos, como o Imo e o WhatsApp, já conquistaram a preferência entre surdos e ouvintes. Para Kenski (2008), nos ambientes virtuais que podem ser acessados pelo smartphone, circulam inúmeras formas de comunicação instantânea, oportunizando a comunicação entre pessoas em qualquer parte do mundo, pois

Uma imensa e complexa rede de meio de comunicação, instalada em quase todos os países do mundo, interliga pessoas e organizaçóes permanentes. Um único e principal fenômeno tecnológico, a internet, possibilita a comunicação entre pessoas para mais diferenciados fins: fazer negócios, trocar informaçốes, me experiências, aprender juntas, desenvolver pesquisas e projetos, namorar, jogar, conversar, enfim, viver novas vidas, que podem ser partilhadas em pequenos grupos ou comunidades virtuais (KENSKI, 2008, p.33).

4 Facebook é uma rede social disponível para a Web, com versão móvel. 
Embora o aplicativo Imo náo possua a mesma popularidade, oferece todas as possibilidades descritas pelo autor. E por mais que ele não esteja presente no ranking como um dos mais utilizados pela população, os surdos do grupo demonstraram sua preferência. A conversa por vídeo instantânea e com qualidade visual é uma excelente ferramenta para eles e os ouvintes se comunicarem pela língua de sinais, dispensando a preocupação com a escrita, leitura e compreensão do texto redigido. Como bem explicitaram alguns,

$[\ldots .$.$] às vezes, o português, as palavras o surdo tem dificuldades em entender,$ entáo para o surdo o Imo é melhor (SURDO A 01).

O WhasApp, porque é mais fácil se comunicar, mais o Imo abre a tela e conversa em LIBRAS e isso é bom e muito importante (SURDO A 04).

[...] o melhor e que eu mais utilizo é o Imo, porque é muito mais fácil para me comunicar, uso sinais, tenho contato com as pessoas troco sinais, eu acho Imo melhor (SURDO A 08).

É muito melhor conversar tanto com surdo como com ouvinte pelo Imo. Pelo WhatsApp, português é difícil, tem que ter paciência, melhor fazer e mandar vídeo (SURDO A 03).

Apesar de muitos surdos pontuarem que preferiam o Imo ao WhatsApp, as opinióes se dividiram. Alguns citaram o primeiro por lhes possibilitar o uso da Libra como meio de comunicação. Outros escolheram o WhatsApp, já que, apesar da exigência de maior esforço para compreenderem o português, conseguiam conversar com todos os surdos e ouvintes de forma semelhante. No entanto, ao longo da pesquisa, observarmos que o uso do Imo ocorria principalmente entre surdos e intérpretes, cuja interação ocorria sempre por meio da língua de sinais.

Por sua vez, o WhatsApp era de uso mais comum tanto entre os surdos como entre eles e os ouvintes. Sendo assim, a preferência ocorria quando tinham a possibilidade de escolher o aplicativo por meio do qual se comunicariam. Se um deles quisesse conversar com outro, normalmente escolhia o Imo. Quando a comunicação fosse com alguém que não dominasse a língua de sinais, usavam o Whats $A p p$ da mesma forma que os ouvintes. Independe do aplicativo escolhido, o fato é que a interação acontecia entre ambos por intermédio desses aplicativos. As enunciaçóes que seguem expressam a maneira como esses aplicativos utilizados pelo grupo potencializava a problematização de assuntos do cotidiano da cultura surda, bem como a comunicação e interação com o outro.

Bom dia à Deus! Eu gosta muito de Whatsaap é pra conversa com os amigos com minha família que ver os amigos surdos na Libras vídeo!!! (SURDO A05)

Bom dia tudo bem eu gosto muito Whatasapp conversar surdos e ouvinte amigo normal também famílias e escola alunos amigo normal sim também ter Whatasapp vídeo libras conversar sim já! (SURDO A01) 
Cloro sim. Tenha usar grande Whatsp é eu tô usar vívio Whatsp mas conversar ouviu ou surda qualquer vários tenho pessoas gostar semper. $\mathrm{O}$ hrs liberdade escolher tbem. (SURDO A08)

Bom dia... Eu gosto já tenho Whasapp (SURDO A09)

Tá bm (SURDO A08)

Porque você conversou com surdos ouvintes no Whastsapp? (SURDO A08)

Nas enunciações acima, é possível identificar o tom animado dos surdos ao relatarem os motivos pelos quais optavam pela utilizaçáo do WhatsApp. Outro aspecto que, talvez, justificasse a animação e preferência pelo uso desse aplicativo se devesse à possibilidade de conversarem com a família e os com ouvintes sem a preocupação com erros ortográficos e gramaticais da língua portuguesa.

Sim ajuda, às veze, as pessoas surdas não conhece as palavras, ai tem a comunicação oi, tudo bem, obrigada. Só mensagem com palavras, eu entendo um pouco e fica claro (SURDO A 04).

Eu gosto do WhasApp, porque, às vezes, os surdos aprendem algumas palavras e aprende algumas coisas (SURDO A 05).

Sim, ajudam. Às vezes, as pessoas mandam mensagens com palavras, e se eu não entendo, pergunto para alguém, peço ajuda, a pessoa me explica e tudo bem, eu entendo (SURDO A11).

Sim, ajuda sim. No WhasApp, às vezes, eu não entendo todas as frases, aí eu tenho dúvida com as palavras e eu vou aprendendo as palavras (SURDO A 12).

Mesmo não tendo muito domínio do português, os surdos conseguiam estabelecer uma conversa com o outro pelo aplicativo. Movidos pela vontade de manter uma comunicação, desfaziam suas dúvidas com as pessoas próximas, aprendiam significados de novas palavras e ampliavam sua escrita e leitura do português e, consequentemente, aprendiam por meio do aplicativo. Thoma e Sperb (20012, p. 56) apontam que é "[...] importante pensar sobre o ensino da língua portuguesa especialmente quando tantas teorias falam de formas diversificadas e até divergentes sobre a melhor forma de efetivá-lo". Os estudos aqui mostram que os aplicativos utilizados podem se tornar ferramentas potencializadoras de ensino para os surdos, uma vez que rompem a barreira da comunicação e lhes permite aprender de forma natural o significado e sentido das palavras em português.

Stumpf (2010, p. 05) explica que fazer uso de uma ferramenta de bate-papo para "encontrar os amigos é uma experiência que os ouvintes apreciam e, muito mais os surdos, porque para a maioria deles essa atividade permite fazer contatos com seus pares, coisa que a maioria náo teve oportunidade de fazer durante todo o dia”. Os aplicativos oportunizam um diálogo escrito de forma rápida, abreviada e sem uso de conectivos e artigos que, por vezes, assemelha-se à escrita dos surdos, e esse formato contribui para seu entendimento na leitura das mensagens recebidas. 
Sendo assim, ao usar o aplicativo WhatsApp, o surdo passa a se relacionar com o ouvinte, pois, embora este não domine a língua de sinais, ambos conversam de forma semelhante, ou seja, trocam mensagens e interagem pelo aplicativo, conseguindo, assim, estabelecer uma comunicaçáo. Se por um lado, o uso do aplicativo não lhe concede a audição; por outro, permite-lhe que se faça entender por meio das mensagens e dos vídeos da mesma forma que os ouvintes.

A dinâmica dos aplicativos é atrativa, pois beneficia o uso de recursos visuais, animação de imagens, que, muitas vezes, contribuem para a compreensão do surdo, já que este faz uso de uma língua espaço-visual. Sendo assim, compreende a fala do outro e manifesta de maneira semelhante, por meio de palavras, imagens e vídeos, ao que os ouvintes fazem nos aplicativos.

Strobel (2009, p. 27) afirma que a forma como o surdo entende e modifica o mundo tem o intuito de "[...] torná-lo acessível e habitável ajustando-o com suas percepções visuais, que contribuem para a definição das identidades surdas [...]. Isso significa que abrange a língua, as ideias, as crenças, os costumes e os hábitos do povo surdo". Assim, as buscas e trocas proporcionadas pelos aplicativos lhe permitem uma melhor interação com quem antes era difícil. As enunciaçôes abaixo expressam o quanto o aplicativo Whas App potencializa a troca de informação e interação entre os surdos, família e ouvintes.

Com minha família longe, meu primo, minha cunhada, minha tia que mora na fazenda. E é bom porque a gente conversa, pergunta e a saúde está boa? Preocupa nada. Conversa normal (SURDO A 04).

Sim, ajuda, porque tem interação, troca, bate papo e tem muita conversa (SURDO A 12).

Sim, eu converso com minha prima, ela me dá conselho, a gente conversa. Com minha família, eu converso um pouco, mando mensagens. Quando são poucas palavras, eu consigo entender, porque conheço pouco português, mas quando são muitas palavras não entendo (SURDO A 10).

Para Moran (2000, p. 11) "todos estamos experimentando a sociedade mudando nas suas formas de organizar-se, de produzir bens, comercializá-los, de divertir-se de ensinar e de aprender". Se antes, para realizar determinadas atividades, os surdos precisavam se fazer presentes no local, hoje, eles podem fazê-las à distância, independentemente do espaço geográfico. Outro aspecto a considerar é que o uso dos aplicativos os aproximou da família, pois, mesmo sendo os únicos a dela fazerem parte, participam dos grupos criados no aplicativo WhatsApp, recebendo e enviando notícias, imagens, fotos, vídeos. Dessa forma, integram-se aos assuntos dos quais antes eram excluídos pela barreira da comunicação. Os excertos a seguir comprovam tais fatos.

Em efeito, os surdos conseguem problematizar questôes a respeito da sua vida, cultura, família, língua, entre outros, usando os aplicativos, e se expressam sem medo de julgamento. Por exemplo, quando o tema a ser discutido no grupo do WhasApp estava relacionado às comemoraçóes que ocorreriam durante o mês de 
setembro para a comunidade surda do Brasil, logo surgiram as manifestaçóes. Alguns postaram suas opiniōes e conhecimentos, outros realizaram pesquisas e colocaram os textos extraídos da internet conforme é possível verificar nas enunciaçóes a seguir.

Setembro azul para mostrar a todos a importância da valorização da LIBRAS e da Cultura Surda! (SURDO A01)

E cultural clora (SURDO A03)

Cadê pessoa como jeito cadê pode o opinião (SURDO A08)

Dia 26 setembro importante cultura surda (SURDO A06)

Setembro Azul mostrar a todos Surdo importância. (SURDO A10)

Setembro Azul importante cultura surda. (SURDO A07)

Dia 26 setembro dia surdos especial (SURDO A04)

Nós temos direito à Escola Bilíngue para Surdos. Vamos lutar pela aprovação da proposta de emendas substitutivas do Plano Nacional Educação - PNE! Muita bem (SURDO A05)

$\mathrm{Na}$ última postagem, evidencia-se que a autora da escrita não é a surda. Ao ser questionada se havia realizado uma pesquisa em algum site, respondeu-nos afirmativamente. Chegamos a essa conclusão por dois motivos: primeiro, porque conhecíamos as suas dificuldades e limitaçôes na escrita da língua portuguesa; segundo, pelo emprego de termos, como ementas substantivas, que não faziam parte de seu vocabulário e, possivelmente, desconhecesse o significado. Porém, o assunto condiz com a discussão a respeito das lutas e conquistas, bem como os direitos adquiridos pelo povo surdo, citados anteriormente. Os excertos a seguir atestam essa ideia:

Sim! Só pesquisa. Primeiro rio de janeiro tem surdo império de D.Pedro vocês conhecer império de D. Pedro??? (SURDO A05)

Humm. Capoir mas você não aprender nada KK (SURDO (A08)

Preciso importante aprender pesquisa (SURDO A05)

Ata Tá mas você faculdade saber o tudo só pensar bem (SURDO A08)

A atitude de copiar da internet nos reporta a Kenski (2008, p. 47) quando ele cita que o uso das redes [...] "transformam a relaçáo com o saber. As pessoas precisam atualizar seus conhecimentos e competências periodicamente." Ao buscar e copiar o texto da internet, a surda mostrou sua disposição de se informar e participar da discussão, além de obter mais conhecimento a respeito do tema em debate. Naquele momento, seu objeto de desejo era contribuir para a discussão referente ao tema exposto. 
Nisto não há nada de espantoso, visto que o discurso - como a psicanálise nos mostrou - não é simplesmente aquilo que manifesta (ou oculta) o desejo; é também, aquilo que é o objeto do desejo; e visto que - isto a história não cessa de nos ensinar - o discurso náo é simplesmente aquilo que traduz as lutas ou os sistemas de dominação, mas aquilo por que, pelo que se luta, o poder do qual nós queremos apoderar (FOUCAULT, 2008, p. 10).

A influência nas enunciaçóes da Surda A 05 foi também observada pelos colegas do grupo, uma vez que perceberam que ela copiara o texto em questáo. Como argumento de defesa, declarou ser importante fazer pesquisa, porque se aprende com ela. Apesar de entender e aceitar tal justificativa, A 08 comentou que, pelo fato de a colega estar cursando faculdade, precisava pensar um pouco mais sobre o assunto e escrever com suas palavras. A respeito do uso e influências das tecnologias digitais, Kenski (2008) afirma que

A tecnologia digital rompe com as formas narrativas circulares e repetidas da oralidade e com o encaminhamento contínuo e sequencial da escrita e se apresenta como um fenômeno descontínuo, fragmentado e, ao mesmo tempo dinâmico aberto e veloz. Deixa de lado a estrutura serial e hierárquica na articulação dos conhecimentos e se abre para o estabelecimento de novas relações entre conteúdos, espaços e pessoas diferentes (KENSKI, 2008, p. 3132).

Ao analisar as enunciações surdas, foi possível constatar que as tecnologias digitais contribuíram de forma eficiente para a interação e aprendizagens do grupo pesquisado. Muitos de seus integrantes usavam os aplicativos WhatsApp e Imo em vários momentos do seu dia, com pessoas surdas e ouvintes, visando sempre comunicar e interagir pelos aplicativos, mesmo com surdos de outras cidades. Para Pampanelli (2004, texto digital), com essas ferramentas, surgiu "um novo meio, ele proporcionou o surgimento da cultura social do 'estar junto". A tecnologia aqui media e reúne indivíduo com indivíduo [...]". Por meio do uso dessas tecnologias digitais, os surdos, além de interagir com todos os seus contatos, podem ampliar seu conhecimento em diversas esferas e se manterem informados sobre os assuntos que os atraem.

Ao apontarem a dificuldade em compreender algumas palavras da língua portuguesa, os adultos assumiram que sempre que isso ocorria pediam ajuda a quem estivesse próximo. Além de contribuir para a ampliação do seu vocabulário, despertava-lhes a curiosidade a respeito dos significados dos vocábulos, minimizando, dessa forma, os problemas que enfrentavam na escrita.

\section{(In) conclusóes}

Os surdos, usualmente, são prejudicados em sua vida social, familiar e escolar em virtude das dificuldades de comunicação, bem como da falta de conhecimento em relação à sua cultura por parte dos ouvintes. Entretanto, as ferramentas digitais disponíveis para comunicação e interação, assim como o relacionamento entre os integrantes desse grupo, contribuem para sua interação com a família, amigos e 
outros de forma mais efetiva, levando-os a aprender a respeito da vida, da sociedade, entre outros.

Os surdos pesquisados usavam os aplicativos WhatsApp e Imo em vários momentos do seu dia, com pessoas surdas e ouvintes, sempre buscando se comunicar e interagir pelos aplicativos, mesmo com surdos de outras localidades. "A tecnologia aqui media e reúne indivíduo com indivíduo [...]". Por meio do uso dessas tecnologias digitais, os surdos podem, além de interagir com todos os seus contatos, ampliar seu conhecimento em diversas esferas e se manterem informados sobre os mais variados assuntos.

Assim, diante de tanta tecnologia acessível, a comunicação e a interação social passaram a ser possíveis entre pessoas de diferentes culturas e línguas. $\mathrm{O}$ uso das tecnologias digitais é capaz de lhes oferecer uma socialização maior, além de mais autonomia em diversos aspectos da sua vida, como pesquisar e encontrar sozinhos determinado endereço residencial por meio de uma busca na internet.

O uso dos aplicativos WhatsApp e Imo ampliam também as possibilidades dos processos de ensino e aprendizagem, uma vez que os surdos buscam, discutem e se informam sobre os mais diversos temas. Portanto, a utilização desses aplicativos facilita a comunicação entre eles e os ouvintes, mesmo com aqueles que desconhecem ou não dominam sua língua de sinais, as LIBRAS.

Os surdos do grupo pesquisado também usavam os aplicativos WhatsApp e Imo para promover encontros presenciais entre eles, tirar dúvidas, conversar ou ter notícias da família, além de visar ao entretenimento e estabelecer a comunicação com pessoas surdas e ouvintes de vários lugares diferentes. Logo, a utilização dos aplicativos lhes permite manterem contato permanente com outros grupos sem deixar de lado sua cultura e suas especificidades. Ali, do outro lado do smartphone, o surdo é ele mesmo, sem vergonha de se expor.

\section{REFERÊNCIAS}

ANGROSINO, Michael. Etnografia e observaçáo participante. Porto Alegre: Artmed, 2009.

BELLONI, Maria Luiza. Crianças e mídias no Brasil: cenários de mudança. (Livro eletrônico) - $1^{\circ}$ edição- Campinas, SP: Papirus, 2014.

CRESWELL, John W. Projeto de Pesquisa: métodos qualitativo, quantitativo e misto. 3. ed. Porto Alegre: Artmed, 2010.

FOUCAULT, Michel. História da Sexualidade 1: A Vontade de Saber.13º ed. Rio de Janeiro: Graal. 1999.

FOUCAULT, Michel. A ética do cuidado de si como prática da liberdade. In: Ditos \&

Escritos V - Ética, Sexualidade, Política. Rio de Janeiro: Forense Universitária, 2004.

FOUCAULT, Michel. A ordem do discurso. 16º ed. São Paulo: Loyola, 2008. 
GADOTTI, Moacir. A questáo da Educaçáo Formal/Não-Formal. Disponível em http://www.paulofreire.org/Moacir_Gadotti/Artigos/Portugues Educacao_Popular_e_ EJA/Educacao_formal_nao_formal_2005.pdf. Acesso em 19 de maio de 2017.

KENSKI, Vani Moreira. Educação e Tecnologias: o novo ritmo da informação. Campinas: Papirus, 2008. 144 p.

KENSKI, V. M. Tecnologias e tempo docente. Campinas: Papirus, 2013.

MORAN, José Manuel. Novas Tecnologias, Mediação Pedagógica. Papirus. Campinas SP. 2000.

MOREIRA, Herivelto; CALEFFE, Luiz Gonzaga. Metodologia da pesquisa para professor pesquisador. Rio de janeiro: DP\&A, 2006.

LOPES, Maura Corcini; VEIGA-NETO, Alfredo. Marcadores culturais surdos: quando eles se constituem no espaço escolar. Perspectiva, Florianópolis, v. 24, n. Especial, p. 81100, jul./dez. 2006.

MORAN, José Manuel. A educação que desejamos: novos desafios e como chegar lá. 5 ed. Papirus. Campinas, SP. 2012.

OLIVEIRA, Annelore Spieker de. Smartphones e trabalho imaterial: uma etnografia virtual sobre sujeitos usuários de dispositivos móveis convergentes. Universidade Federal do Rio Grande do Sul. Faculdade de Biblioteconomia e Comunicação.

(Dissertação de Mestrado). Programa de Pós-Graduação em Comunicação e Informação. 2007. Disponível em: <http://www.lume.ufrgs.br/handle/10183/12142>. Acesso em: 04 de abril de 2016.

PAMPANELLI, Giovana Azevedo. A evoluçáo do telefone e uma nova forma de sociabilidade: o flash mob. Razón y Palabra, 2004. Disponível, em <http://www. razonypalabra.org.mx/anteriores/n41/gazevedo.html> Acesso em 15 de março de 2016.

QUADROS, Ronice Muller. Educação de surdos: a aquisição da linguagem. Porto Alegre, Artes Médicas, 1997.

STUMPF, Marianne Rossi. Educação de Surdos e Novas Tecnologias. Universidade Federal de Santa Catarina Licenciatura e Bacharelado em Letras-Libras na Modalidade a Distância: Florianópolis, 2010.

STROBEL, Karin. As imagens do outro sobre a Cultura Surda. 2. ed. rev. Florianópolis: Ed. da UFSC, 2009.

THOMA, Adriana da Silva; SPERB, Carolina Comerlato. Bilinguismo, Cultura Surda, e Práticas de Letramento na Educaçáo de Surdos. In III Colóquio Internacional sobre Letramento e Cultura Escrita, 2010, Belo Horizonte - MG. Anais do III Colóquio Internacional sobre Letramento e Cultura Escrita - Diversidade e diferença na educação: cultura escrita, letramento, políticas linguísticas e identidades. Belo Horizonte - MG: Editora da UFMG, 2010, p.1-14. 
VEIGA-NETO, Alfredo. Apresentação. In: THOMA, Adriana; LOPES, Maura (Orgs.). A invençáo da surdez II. Espaços e tempos de aprendizagem na educaçáo de surdos. Santa Cruz do Sul: EDUNISC, 2006. p. 7-8.

YIN, R. K. Estudo de caso: planejamento e métodos. 4. ed. Porto Alegre: Bookman, 2010. 